\title{
Laicidad, ¿neutralidad? y deliberación pública. Un diálogo con Alfonso Ruiz Miguel. Comentario a Alfonso Ruiz Miguel, Cuestiones de principios: entre política y Derecho
}

(2020) Centro de Estudios Políticos y Constitucionales Madrid, 615 pp.

\author{
Rodolfo Vázquez \\ Instituto Tecnológico Autónomo de México \\ rvazquez@itam.mx
}

\section{Cita recomendada:}

Vázquez, R. (2021). Laicidad, ¿neutralidad? y deliberación pública. Un diálogo con Alfonso Ruiz Miguel. Comentario a Alfonso Ruiz Miguel, Cuestiones de principios: entre política y Derecho. Eunomía. Revista en Cultura de la Legalidad, 20, pp. 415-425.

doi: https://doi.org/10.20318/eunomia.2021.6085

Recibido / received: 01/02/2021

En el apartado 6, «Laicidad y libertad religiosa», correspondiente a la primera parte del libro más reciente de Alfonso Ruiz Miguel, Cuestiones de principios: entre política $y$ Derecho, el autor señala que el texto «recoge ideas por mí expresadas en anteriores escritos». Hasta donde he podido averiguar, podríamos remontar esas ideas unos 15 años atrás, a junio de 2006, con un texto presentado en la Universidad de Milán con motivo del nombramiento del profesor Elías Díaz como Doctor honoris causa por dicha universidad (Ruiz Miguel, 2007). Con toda seguridad el tema de la laicidad y sus vínculos con el liberalismo y la democracia han acompañado a Alfonso a lo largo de su fecunda trayectoria académica, pero creo que en los últimos años ha sido uno de los leit motiv de sus investigaciones. Quiero aprovechar esta oportunidad a la que nos convoca nuestro querido amigo y colega José María Sauca, desde la Universidad Carlos III de Madrid, para seguir dialogando con Alfonso sobre este tema e intentar hacer más explícitos los puntos de acuerdo y aquéllos -los menos- en los que creo que todavía mantenemos algunas diferencias.

1. ¿Qué es la laicidad?

En uno de sus trabajos seminales sobre el tema, dice Alfonso: «Defenderé aquí lo que considero la acepción más extendida y central de la laicidad: la doctrina de la 
neutralidad del Estado ante las diversas creencias de los ciudadanos en materia de religión». Esto quiere decir que: 1. las creencias religiosas, su transmisión y enseñanza se localizan en el ámbito privado; 2. en tanto expresión de un derecho individual, el Estado debe proteger la libertad ideológica, que se manifiesta también en la no profesión de creencia religiosa alguna, así como las ideas antirreligiosas; 3. las faltas a la moral de inspiración religiosa no tienen trascendencia política y más bien el Estado debe definir los delitos mediante criterios universalizables; 4 . se debe privilegiar el criterio de argumentación y consentimiento de los individuos, a través del voto y del principio de mayoría, frente a la pretensión de la custodia de verdades reveladas por la divinidad a través de sacerdotes y jerarquías eclesiásticas o comunidades fundamentalistas (Ruiz Miguel, 2007, pp. 159-160).

Con respecto a lo público y lo privado, señala Alfonso con razón, si bien el ámbito primordial de las creencias religiosas es el privado, la libertad religiosa comprende también el derecho a expresar e intentar expandir las propias creencias en el ámbito público: «desde la construcción de lugares de culto y de enseñanza religiosa hasta las procesiones y el proselitismo casa por casa» (2007, pp. 159-160). Lo que importa entender es que el perímetro correcto del ejercicio de esos derechos debe situarse estrictamente dentro de la sociedad civil y no traspasar a la utilización del Estado. Éste debe mantener una posición de neutralidad frente a todos los cultos, sin privilegiar alguna confesión religiosa por encima de las demás. El Estado estará legitimado a intervenir cuando se violenten o transgredan los derechos humanos y, por lo mismo, las acciones dejen de ser privadas para adentrarse en el ámbito públicoinstitucional.

Por lo que hace a la libertad religiosa, la extensión de la misma abarca tanto a creyentes como no creyentes, en el marco de una sociedad democrática y plural. El alcance de la libertad religiosa referida a los no creyentes abarca tanto a los ateos como a los agnósticos. En un comentario marginal con respecto a estos últimos, y comentando sobre la idea de neutralidad liberal que retomaré más adelante, Alfonso sitúa a los agnósticos, me parece que erróneamente, en una suerte de limbo, de «indiferencia», «indecisión» o «duda». Transcribo el párrafo:

Su neutralidad en materia religiosa [la del Estado neutral o laico] debería vedarle no solo el ser confesional, ateo o laicista, sino incluso la posición de indecisión o duda en el individuo que está a medio camino entre religión y no religión, que es el agnosticismo. Por eso yo he mantenido en ocasiones anteriores que el Estado verdaderamente laico debe ser meta-agnóstico, esto es, debe ser ajeno a cualquier pregunta y respuesta relativa a la religión. $\mathrm{O}$, dicho de otra manera, el Estado no puede ni debe solo limitarse a dudar, como puede hacer el individuo agnóstico, sino que asume el deber de no pronunciarse sobre la materia religiosa, ni siquiera para afirmar que duda (Ruiz Miguel, 2020, p. 185).

Estoy de acuerdo en la idea de que el Estado ni siquiera debe pronunciarse para afirmar o negar cualquier tipo de duda. Lisa y llanamente debe abstenerse. Dicho esto, sin embargo, y consciente que no es el punto central en la argumentación, quiero reivindicar a los agnósticos, distinguirlo de los ateos y de los creyentes, y mostrar que nada es más compatible con un Estado laico que la actitud agnóstica, muy lejos de un estado de duda o indiferencia. Para este propósito, me apoyaré en el último libro de Ronald Dworkin, Religión sin dios (2014).

Para la mayoría de la gente, piensa Dworkin, el vivir bien requiere una vida situada, y situarse en la vida, tiene que ver para muchos con una concepción del universo, con un «parámetro incluyente para todos». Citando a Thomas Nagel, para Dworkin este deseo de una conexión generalizada es propio del «temperamento religioso». Este deseo no es privativo de los creyentes, también lo es para los no 
creyentes que se enfrentan, igualmente, al dramático interrogante: «¿Cómo puede uno incorporar a su vida de individuo el pleno reconocimiento de la relación que tiene con la totalidad del universo?» (Dworkin, 2014, p. 268). Por ello: «Aun cuando no haya un planificador eterno, nosotros somos planificadores: planificadores mortales con una vívida sensación de nuestra dignidad y de la buena y la mala vida que podemos crear o padecer» (2014, p. 270). La convicción de un dios trascendente al mundo, su unicidad o multiplicidad -teísmo o politeísmo- presuponen para Dworkin, un compromiso previo con la realidad, independiente del valor de lo divino.

El entusiasmo, el fervor y la emoción que acompaña a la inteligencia, continúa Dworkin, descansan en el descubrimiento de aquello que tiene un valor en sí mismo, de algo bueno, correcto, de una belleza cósmica, verdadera y sublime, que se nos revela o se nos manifiesta objetivamente. En este sentido, pienso que la actitud agnóstica, la del individuo instalado plenamente en la mundanidad y la finitud sin sentido de trascendencia o de inmortalidad -dios es una hipótesis inverificable, empírica o racionalmente-, sin «indecisión» y sin «echar de menos a Dios», pero abierto a lo inefable, es, precisamente, el punto de encuentro entre teístas y ateos como compañeros de viaje en las convicciones más profundas. La experiencia de lo sublime, del asombro, de lo luminoso, de lo bello y bueno en sí, no necesita esperar a ningún dios. $\mathrm{Si}$, como decía Bobbio, «el espíritu laico no es en sí mismo una nueva cultura, sino la condición de convivencia de todas las posibles culturas», diría que la actitud agnóstica sería la condición de posibilidad para toda coexistencia pacífica entre las diversas convicciones religiosas: la del teísta y el politeísta, pero también la del ateo, que niega sistemáticamente la existencia de alguna divinidad o ser trascendente. La laicidad en el ámbito institucional se correspondería plenamente con una actitud agnóstica que, al decir de Enrique Tierno Galván: «es el testimonio de la madurez de la secularización» (1975, p. 66), muy distante, ciertamente, de una actitud de duda o de indiferencia. En cualquier caso, reafirmo con Alfonso que el Estado ni siquiera debería asumir un sentido secular de la religión. Cierro el paréntesis.

\section{Neutralidad no es lo mismo que imparcialidad}

También conviene aclarar que imparcialidad no es sinónimo de neutralidad entendida como pasividad o inacción. En Laicismo y constitución, Alfonso no parece distinguir entre neutralidad e imparcialidad: «mi modelo ideal opta por una laicidad neta y rotunda del Estado, entendida como la más estricta neutralidad posible de los poderes públicos ante toda convicción relativa a la religión, incluidas las creencias no religiosas [...] al Estado le está vedada esa posibilidad [la de ser laicista], debiendo limitarse a ser laico, en el sentido de neutral e imparcial entre las diversas creencias en materia de religión» (2009, pp. 34 y 62).

Ser neutral es abstenerse de influir en los resultados porque no se asume intencionalmente ninguna participación en el conflicto; en otros términos, la neutralidad es una característica formal del comportamiento y no está implicado ningún valor material en su concepto (Kolakowski, 1975, pp. 72-73). La neutralidad entendida como inacción se distingue de la imparcialidad que supone algún tipo de actividad. Ejemplifico con un caso en sede judicial y que Alfonso ya conoce. Se trata del voto concurrente del ministro José Ramón Cossío con respecto al régimen de convivencia, en un matrimonio, mujer católica y padre judío, en el que el demandante pedía que se adaptara el régimen de convivencia con su hija, para que ella pudiera conocer y practicar los ritos propios de la religión judía, al igual que lo hacía su madre, con respecto a los ritos católicos. El argumento de Cossío es el siguiente:

Mantener que la neutralidad estatal frente a las variadas creencias de los ciudadanos exige al Estado no actuar o no pronunciarse es olvidar que, en una gran cantidad de 
ocasiones, esa abstención no hace sino convalidar un estado de cosas profundamente asimétrico desde el punto de vista de los derechos y libertades de las partes. [...] lo que la Constitución exige fundamentalmente es imparcialidad, no inacción, y que el principio de separación entre las Iglesias y el Estado consagrado en el artículo 130 de la Constitución Federal no exime en muchos casos a los órganos estatales del deber de regular en distintos niveles (legislación, reglamentación, aplicación judicial) cuestiones que se relacionan con la vida religiosa de las personas Cossío (2008, pp. 64$65)^{1}$.

Hay que tener presente que Cossío no está diciendo que se deba de dotar de recursos al padre, ni el modo como debe educar a su hija, sino, exclusivamente, igualar activamente en los derechos. De no ser así, el Estado incurriría en un paternalismo, o bien, en un perfeccionismo jurídico, injustificables desde un punto de vista liberal.

En ese mismo sentido se expresan Michelangelo Bovero y Luis Salazar Carrión. El adjetivo laico puede entenderse desde un punto de vista negativo mínimo de modo tal que para que un Estado sea laico basta con que sea neutral en relación a los diferentes credos religiosos. Sin embargo, reducir la laicidad de esa manera, piensan estos autores, abre las puertas al nihilismo, al relativismo, al indiferentismo o al cinismo. Para evitar caer en tal situación, es necesario que el pensamiento laico no se entienda como la ausencia de valores, sino como la manera de presentar y defender ciertos principios y valores: el pensamiento laico se funda en un principio práctico: la tolerancia; y en un principio teórico: el antidogmatismo. Siendo así, lo propio de una ética laica es colocar como principio fundamental el respeto a la autonomía de los individuos en tanto seres racionales. Bajo este supuesto, tal ética exige una educación ilustrada, condiciones de legalidad y un derecho positivo que reconozca y garantice efectivamente los derechos fundamentales de todas las personas por igual (Bovero, 2002 y Salazar Carrión, 2007, pp. 149 ss.). Se puede objetar que si el Estado interviene para corregir las desventajas en relaciones asimétricas entonces el Estado deja de ser neutral (laico). ¿Qué igualdad es la que debe garantizar el Estado?: ¿de recursos?, ¿de oportunidades? Simplemente, como sugieren Bovero y Salazar, una igualdad en los derechos.

Alfonso reconoce en un escrito posterior, «La laicidad y el eterno retorno de la religión» (2010/2013), que en su propuesta de laicidad neutral el Estado debe mantener políticas activas, además de referentes a la protección de los derechos básicos, también en relación al fomento de la ciencia. Y precisamente para garantizar los derechos básicos manifestaba en ese escrito su discrepancia con respecto a las limitaciones constitucionales que en México afectan a los ministros de culto en el sufragio pasivo y en los derechos de asociación y expresión en materia política. Regresaré sobre este último punto más adelante. Lo que me parece necesario dejar claro es que la comprensión de la laicidad en términos de neutralidad pasiva o de imparcialidad activa no es una cuestión solo semántica. Creo, por el contrario, que se definen en este punto, de forma sustantiva, dos concepciones diversas del liberalismo: la vertiente libertaria del liberalismo ha insistido en la neutralidad estatal entendida como no interferencia y pasividad, mientras que la vertiente igualitaria la ha comprendido en un sentido proactivo acorde con su compromiso con los deberes positivos del Estado, y no solo con los negativos. Si es este último sentido de liberalismo el que defiende Alfonso -como se hace explícito en otros apartados de su último libro- nuestro acuerdo no puede ser mayor.

\footnotetext{
${ }^{1}$ El texto reproduce el voto concurrente formulado por el ministro José Ramón Cossío Díaz en el amparo directo en revisión 502/2007, fallado por la Primera Sala de la Suprema Corte de Justicia en México, el 28 de noviembre de 2007.
} 
Dicho lo anterior, creo que para ningún jurista es novedad que el Estado puede y debe intervenir en materia religiosa para dirimir conflictos. En sede judicial ha habido casos muy interesantes, por ejemplo, con respecto a los testigos de Jehová y las obligaciones cívicas de honores a la bandera y el canto del himno nacional en las escuelas públicas; la portación o exhibición de símbolos religiosos en instituciones estatales, etc. Si el Estado ha intervenido es porque el Estado debe garantizar tanto el derecho a la libertad de conciencia como otros derechos con los cuales puede entrar en conflicto.

Es claro que el Estado debe salvaguardar el ámbito de lo privado, pero esta protección no debe servir como excusa tampoco, para violar derechos de terceros: el límite de la privacidad, como dijimos, es precisamente la violación de derechos de terceros. A este respecto, un caso muy interesante, además del señalado sobre el matrimonio mixto, judío y católico en el voto concurrente del ministro Cossío, es el caso Wisconsin vs Yoder, de 1972, con respecto a la educación en la comunidad Amish, que retiraban a sus hijos de la educación pública los últimos dos o tres años de escolaridad básica. En este caso se decidió en favor de la comunidad, pero quizás lo más conocido del caso y por el cual se le cita, es por el voto en disidencia del Juez William $O$. Douglas del que vale la pena citar un fragmento:

Un niño Amish puede querer ser un pianista o un astronauta o un oceonágrafo. Para lograrlo deberá apartarse de la tradición Amish... Si sus padres conservan al niño fuera de la escuela más allá de la primaria, entonces el niño quedará imposibilitado de participar en el nuevo y apasionante mundo de la diversidad que tenemos hoy día... Si es constreñido a la forma de vida Amish por aquellos que tienen autoridad sobre él y si su educación es truncada, su vida entera puede ser impedida o deformada ${ }^{2}$.

En esta argumentación se está haciendo valer, también, el principio del interés superior de la niñez y el desarrollo de su autonomía personal. Sobre este punto estoy tan cierto de la necesidad de igualar en los derechos básicos y en el fortalecimiento de la autonomía de los educandos, que he defendido en otros trabajos (Vázquez, 2015, pp. 81-89) la necesidad de que se regulen las escuelas privadas confesionales y se exija una educación laica en las mismas. Fuera de los tiempos oficiales podría acordarse con los padres algún tipo de instrucción religiosa, pero siempre de forma opcional, y sin ningún tipo de sanción para quien decide no aceptarla.

\section{Liberalismo laico: entre laicidad positiva y laicismo}

Acorde con el inciso anterior, vale decir que una cosa es la laicidad positiva y otra la laicidad activa, entendida esta, como dijimos, en términos de imparcialidad y no de neutralidad. La laicidad activa debe distinguirse de la idea popularizada por Sarkozy en la visita de Benedicto XVI a Francia -septiembre de 2008- sobre la laicidad «positiva». Esta última en términos de uno de sus críticos es «aquella fórmula institucional que respeta la libertad de creer o no creer (en dogmas religiosos, claro) porque ya no hay más remedio, pero considera que las creencias religiosas no sólo no son dañinas sino beneficiosas social y sobre todo moralmente» (Savater, 2008, pp. 31-32). Apoyándose en Jean Baubérot, Fernando Savater critica con razón tal tipo de laicidad porque significa:

[...] una forma de neoclericalismo, confesional, pero no confeso. $Y$ eso porque un Estado realmente laico no sólo no puede dejarse contaminar por ninguna religión, ni privilegiar ninguna de las existentes sobre las demás, sino que tampoco puede declarar preferible tener una religión o no tenerla (2008, pp. 31-32).

\footnotetext{
2406 US 205 (1972), cit. por Macedo (1990, p. 268).
} 
De aquí también que sea muy criticable la posición de quienes sostienen que la religión debe jugar un papel relevante en la política y en el derecho, y aun así se vean a sí mismos como defensores de los valores liberales. Michael Sandel cita expresando su acuerdo- un pasaje del discurso de Barak Obama pronunciado el 28 de junio de 2006, que vale la pena transcribir:

Los laicistas se equivocan cuando les piden a los creyentes que dejen su religión en la puerta antes de entrar en la plaza pública. A Frederick Douglas, Abraham Lincoln, William Jennings Bryan, Dorothy Day, Martin Luther King -en realidad, a la mayoría de los grandes reformadores de la historia americana- no solo les movía la fe, sino que repetidamente usan el lenguaje religioso para defender su causa. Así pues, decir que hombres y mujeres no deberían insertar su 'moral personal' en los debates sobre asuntos públicos es absurdo en la práctica. Nuestras leyes son, por definición, una codificación de la moral, buena parte de la cual se fundamenta en la tradición judeocristiana (Sandel, 2011, p. 279).

No, no se equivocan los laicistas. Que los contenidos religiosos coincidan o empaten con contenidos ético-jurídicos no significa en ningún sentido que estos últimos se justifiquen o deban justificarse en los primeros. No debe confundirse el contexto de explicación con el contexto de justificación. Y sí, cuando un ciudadano asume una responsabilidad pública institucional está obligado a justificar secularmente sus iniciativas o decisiones reservando para el ámbito privado sus convicciones religiosas. Si la pretensión tiene una finalidad pragmática en el sentido de que la religión -por supuesto, la mayoritaria- conlleva grandes beneficios en términos de cohesión y estabilidad -muy del gusto de comunitaristas y de cierto republicanismo exagerado- entonces el Estado se deslizaría hacia una laicidad positiva y se sujetaría a las críticas de Savater, citadas más arriba.

Alfonso critica con razón esta «laicidad positiva» de la misma manera que, en el otro extremo, critica también con razón el «laicismo como militancia» en una suerte de fundamentalismo ateo, por ejemplo, en regímenes comunistas. Contra ambos extremos se pronuncia por un:

[...] Estado liberal -en el sentido amplio de democrático-liberal y, por tanto, comprometido con los derechos humanos- [que] debe ser ante todo laico y no confesional. $Y$ eso comporta que debe mantener una forma de laicidad neutral o liberal, que se encuentra en una posición intermedia entre dos extremos: de un lado la laicidad positiva, que desde un punto de vista no es una genuina forma de laicidad sino de confesionalidad encubierta que pretende disfrazarse bajo un nombre que oculta su verdadera naturaleza; y, de otro lado, la laicidad radical o militante (o, en fin, laicismo), que supone una toma de partido beligerante contra las religiones por parte del Estado que, a mi modo de ver, no respeta suficientemente la libertad de conciencia de los individuos (2020, p. 174).

En otra parte del escrito, Alfonso afirma que el Estado liberal debe ser «estricta o puramente laico, en el sentido de indiferente e imparcial...». No sé si sea muy afortunado seguir equiparando liberalismo con neutralidad, o bien, imparcialidad con indiferencia, pero dejaré zanjada esta cuestión, y quiero más bien enfatizar con Alfonso, como él afirma y en lo que estamos de acuerdo, que la laicidad «neutral» no excluye la cooperación entre el Estado y las iglesias, o asociaciones ateas o agnósticas. Por una parte, en términos de ofrecer facilidades en condiciones de igualdad con otras actividades y manifestaciones públicas, pero sin especiales subvenciones o ventajas económicas, y por otra, subvencionando obras y necesidades de interés general (conservación del patrimonio artístico, por ejemplo), pero sin favorecer actividades idiosincráticamente religiosas (Ruiz Miguel, 2020, pp. 186-187). 
Pues bien, sin llegar a posiciones extremas de un laicismo militante, Alfonso tiene serias reservas con respecto a ciertas restricciones en el ordenamiento jurídico mexicano con respecto al acceso de los prelados a medios de comunicación públicos o la limitante para estos sujetos con respecto a la negación del voto pasivo. La pertenencia o no a una iglesia, piensa Alfonso, es algo que se mueve en el ámbito de la sociedad civil y en tanto ciudadanos debe garantizárseles todos los derechos sin restricciones. Si así no fuera, tales restricciones, en una suerte de pendiente llevada al absurdo, debería aplicarse a cualquier ciudadano secular.

El mismo Alfonso reconoce que en el derecho mexicano no se priva al prelado del voto pasivo si previamente renuncia a su condición en un periodo razonable, anterior a la votación. Y esto con el fin de ser igualado en la condición de cualquier ciudadano secular garantizando con ello que las obligaciones del Estado no podrán ser limitadas o tergiversadas por otro tipo de obligaciones no seculares que podrían devenir en cierto tipo de fundamentalismo dogmático y de proselitismo en favor de las mismas. Ejemplos de Estados no seculares abundan y los excesos están a la vista. Por otra parte, me parece claro que si la referencia a una religión estatal o nacional responde a una costumbre histórica, pero en la práctica la tolerancia y el respeto a las diversas creencias religiosas o a los mismos no creyentes se ha institucionalizado y existen sanciones si se incurre en la violación de los derechos correspondientes, entonces una buena dosis de prudencia y de utilitarismo moderado serán necesarios para evitar males mayores y tolerar a estos Estados no seculares, más formales en el papel, que sustantivos en su implementación práctica. La tendencia, sin embargo, debe orientarse a que poco a poco se eliminen cualquier referencia a creencias religiosas en los espacios públicos institucionales y no poner las condiciones, ni mucho menos, favorecer, en los propios términos de Alfonso, actividades idiosincráticamente religiosas porque, como él mismo afirma: «las creencias religiosas, por su carácter peculiar y privativo, sólo deben valer para sus propios creyentes, quienes no pueden imponer tales creencia por la fuerza» $(2017$, p. 423$)$.

Con respecto al otorgamiento a las iglesias de concesiones y permisos para tener canales de televisión y estaciones de radio, en efecto, la normatividad mexicana pone limitaciones que como bien argumenta la Asociación Mexicana de Derecho a la Información (AMEDI): «los medios electrónicos cumplen una misión social de servicio público y no de adoctrinamiento político o religioso" y tal como establece el artículo $3^{\circ}$ constitucional: «los contenidos educativos que transmiten la radio y la televisión se basarán en los resultados del progreso científico, lucharán contra la ignorancia y sus efectos, las servidumbres, los fanatismo y los prejuicios», para concluir que: "Una emisora de índole religiosa es, por definición, adoctrinante, parcial y excluyente, todo lo contrario de nuestros fundamentos constitucionales» (Salazar Ugarte, 2020, p. 237). ¿Significa esto que los ministros de culto tengan prohibido participar en mesas de discusión o debate, lo que, sin duda restringiría seriamente su derecho a la libertad de expresión? De ningún modo. Como bien lo expresa Pedro Salazar:

Lo que debe protegerse es el derecho de las personas que creen en determinada fe y que se organizan para profesarla, pero no a la institución -asociación, comunidad o iglesia- que conforman. Esta última debe ser objeto de regulación y debe cumplir con sus obligaciones con el estado y con la sociedad. De eso hablamos cuando advertimos que la laicidad supone el sometimiento de las organizaciones religiosas al Estado de derecho (2020, p. 238).

Con estas precisiones creo que sería difícil ubicar la normatividad mexicana en una suerte de jacobinismo autoritario muy cercano a una suerte de laicismo militante. De paso no está de más recordar que la lucha por la laicidad en México desde el siglo XIX, con la separación entre iglesias y Estado, así como su reconocimiento explícito a nivel constitucional, ha impedido, a diferencia de muchos 
Estados en la región latinoamericana -con sus excepciones individuales y heroicas-, la injerencia de estas instituciones en un bizarro y tenebroso contubernio con las fuerzas armadas convirtiéndolas en cómplices de las violaciones más aberrantes de los derechos humanos.

\section{Religión y deliberación pública}

De las cuatro características de la laicidad señaladas por Alfonso, y citadas más arriba quisiera detenerme, brevemente, en la cuarta de ellas, a saber, la de privilegiar la argumentación y el consentimiento de los individuos en una sociedad democrática representativa, por encima de la custodia y eventual imposición de verdades reveladas o convicciones metafísicas por parte del Estado, en colusión abierta o solapada con las autoridades eclesiásticas. Como afirma Alfonso: «los intentos de imponer una u otra posición en esta materia por otras vías que no sean la argumentación racional y razonable o el ejemplo de la coherencia y la probidad de las conductas, son una clara negación de la libertad religiosa a la que todos los seres humanos tienen derecho» (2007, p. 192). Quisiera retomar las ideas expresadas en un texto anterior, que Alfonso ha comentado, con el fin de afinar algunos puntos y dar continuidad al diálogo (Vázquez, 2010/2013).

Contraponía en aquel escrito las posiciones de Rawls y Habermas, y presentaba algunas aportaciones de Dworkin, en línea con las de Rawls y que me parecían, y me siguen pareciendo, un buen complemento a su propuesta. Como le aclaré en su momento a Alfonso no pretendía ordenar a estos autores en una suerte de dialéctica en la que Dworkin apareciera como una suerte de síntesis superadora, pero no me pareció nada desacertado como sugería Alfonso colocar a Habermas como antítesis de Rawls. La pregunta que se ponía sobre la mesa de discusión era la siguiente, en términos de Cristina Lafont: «¿Es posible realmente articular una noción de lo 'racionalmente aceptable' que todos los ciudadanos puedan compartir a pesar de no coincidir en una visión del mundo o en una concepción del bien homogénea?» (2007, p. 130).

Como sabemos, en Liberalismo político John Rawls propone su conocido «consenso sobrepuesto» (1995). Esta noción se apoya en el supuesto de que la razón común a todos los seres humanos es suficiente para descubrir y justificar nuestras obligaciones morales y políticas. El consenso obtenido con respecto a la Declaración Universal de los Derechos Humanos de la ONU sería un claro ejemplo de consenso sobrepuesto.

A partir de tal consenso Rawls distingue entre razón pública y razón privada, distinción necesaria para responder la cuestión de qué tipo de argumentos son aceptables e inaceptables en la deliberación pública. Para Rawls nada impide que los ciudadanos que participan en la deliberación pública política ofrezcan razones procedentes de las doctrinas comprehensivas, metafísicas o religiosas, en las que creen, pero siempre y cuando ofrezcan además razones generalmente accesibles a todos los ciudadanos que justifiquen dichas doctrinas. Si estas doctrinas comprehensivas no pueden apoyarse en razones públicas paralelas deben excluirse de la deliberación. El problema de esta concepción salta a la vista: ¿se puede pedir a un ciudadano que sacrifique sus aspiraciones de corrección sustantiva para satisfacer las aspiraciones de legitimidad democrática? Quien no estuviera dispuesto a hacerlo mantiene su sinceridad a costa de ser excluido o autoexcluirse de la deliberación pública; quien estuviera dispuesto a hacerlo apelaría a razones prudenciales para incluirse en el debate democrático, pero a costa de una buena dosis de sinceridad. 
Por su parte, Jürgen Habermas ha dedicado algunos trabajos a esta temática retomando y criticando la propuesta de Rawls (Habermas, 2006, cap. 5) y debatiendo, entre otros, con Joseph Ratzinger (Habermas, 2008). Habermas coincide con Rawls en el sentido de que al determinar las medidas políticas coercitivas que vayan a adoptarse, sólo cuentan las razones generalmente accesibles, las «razones seculares». Pero a diferencia de Rawls, Habermas distingue entre una esfera pública informal y una esfera pública formal o institucional, propia de los funcionarios administrativos, legisladores y jueces. En la primera los ciudadanos pueden apelar a razones exclusivamente religiosas en la deliberación siempre y cuando reconozcan la obligación de traducción institucional. Sólo las razones religiosas que puedan traducirse con éxito en razones seculares podrán pasar el filtro institucional y aspirar a ser coercitivas. Con esta distinción, la propuesta de Habermas permitiría a los ciudadanos en la esfera pública informal expresar y justificar sus convicciones en un lenguaje religioso si no pueden encontrar traducciones seculares para ellas. En este punto, sin embargo, Alfonso comparte con Waldron, y yo con ellos, la idea de que:

[...] resulta errónea la distinción entre ciudadanos ordinarios y legisladores en lo que afecta a la deliberación y al voto desde el punto de vista de una aceptable doctrina democrática: primero, porque al igual que el legislador, el ciudadano no actúa privadamente cunado delibera o ejerce su voto, voto que por lo demás puede tener efectos legislativos en ciertos referendos; y, segundo, porque la relación de representación política, aun no siendo simple ni mecánica, establece una básica conexión entre la deliberación de los ciudadanos y la de los legisladores (Ruiz Miguel, 2010/2013, pp. 61-62).

Por otra parte, ¿hacer tal distinción tan radical, como pretende Habermas, entre ciudadanos religiosos y ciudadanos seculares no pondría en peligro los prerrequisitos de la deliberación pública en términos de simetría de los participantes, como él mismo sostiene como condición necesaria de todo discurso comunicativo?

Habermas responde, de acuerdo con las condiciones formales de todo discurso racional, que no tiene ningún sentido permitir la inclusión de razones religiosas en las contribuciones a la deliberación pública sin el requisito correlativo de exigir que los demás participantes tomen en serio tales contribuciones. Esto es posible si se puede esperar de todos los ciudadanos que no nieguen en principio todo posible contenido cognitivo a esas contribuciones. De aquí que, sorpresivamente, los ciudadanos seculares tienen que cumplir con dos condiciones: 1 . abrirse cognitivamente a la posible verdad de las creencias religiosas y 2 . ayudar a traducir el contenido de las mismas que pueda ser expresado en un lenguaje secular y justificado con argumentos seculares. Habermas es explícito en este punto en su conversación con Ratzinger:

Los ciudadanos secularizados, en tanto que actúan en su papel de ciudadanos del Estado, no pueden negar por principio a los conceptos religiosos su potencial de verdad, ni pueden negar a los conciudadanos creyentes su derecho a realizar aportaciones en lenguaje religioso a las discusiones públicas. Es más, una cultura política liberal puede incluso esperar de los ciudadanos secularizados que participen en los esfuerzos para traducir aportaciones importantes del lenguaje religioso a un lenguaje más asequible para el público en general (Habermas, 2008, p. 33).

Sin embargo, resulta que ahora a diferencia de los ciudadanos religiosos, los ciudadanos seculares son los que no pueden adoptar públicamente la perspectiva cognitiva que se corresponde con sus verdaderas creencias si éstas resultan ser de tipo secular. Estaríamos tratando a los ciudadanos seculares no bajo un criterio normativo sino instrumental $y$, por supuesto, caeríamos en el mismo dilema de la sinceridad que ya hemos visto en Rawls, nada más que ahora aplicado a los 
ciudadanos seculares. Más aún, si después de todo este esfuerzo no se encuentran traducciones seculares para las convicciones religiosas, pues éstas quedan excluidas para adoptar las políticas coercitivas que vayan a adoptarse. Creo que llegamos por una vía un poco más tortuosa a las mismas conclusiones de Rawls. Para Alfonso, y estoy de acuerdo con él, estas premisas acercarían a Habermas, no a una laicidad liberal, sino a una laicidad positiva $o$, si se prefiere, a un laicismo moderado. Asimismo, ¿qué tanto la defensa en Habermas de una posible verdad inherente en las creencias religiosas lo acerque más a Hegel y la distancie de Kant? Es una pregunta que entiendo que filósofos como Reyes Mate han puesto en la mesa de discusión y que valdría la pena profundizar con más detalle en otro escrito.

Dicho lo anterior, es claro que no se está negando el derecho de todo creyente a creer lo que les parezca más adecuado para organizar su plan de vida personal. Lo que se argumenta es que, si son ciudadanos y, por tanto, partícipes en la deliberación pública, "y tienen la pretensión de que sus convicciones sean coercitivas», entonces deben someter los contenidos de las creencias a un escrutinio racional y razonable. La premisa que subyace en el debate es la que prescribe que «es moralmente correcto ejercitar la coerción sólo con base en consideraciones públicamente aceptables», sin violar el principio de simetría entre los participantes.

En esa misma dirección se encamina la propuesta de Dworkin. El problema hoy día, piensa este autor, no se ciñe tanto a si el Estado debe ser tolerante o neutral con respecto a todos los credos religiosos pacíficos y también hacia las personas que no profesan ninguna fe, distinguiendo claramente entre el ámbito público y el privado. Estados Unidos es un buen ejemplo en donde casi el $70 \%$ de los estadounidenses cree que su presidente debe ser una persona religiosa y cuyo sistema ha sido calificado por la encuestadora Celinda Lake como «la democracia industrializada más religiosa del mundo» (2007). Más bien, el problema es saber sobre qué base debe asentarse el cultivo de nuestra tolerancia. ¿Una nación religiosa que tolera la falta de fe? ¿O una nación laica que tolera la religión? Dworkin argumenta, correctamente, a favor de esta segunda opción (2008, pp. 90 ss.).

Alfonso y yo aceptaríamos sin duda la defensa dworkiniana de una «nación laica tolerante», que, con expresiones distintas, Alfonso ya había hecho explícita en su diálogo con Navarro-Valls:

[...] el modelo de «nación religiosa tolerante» de Dworkin refleja de manera muy fidedigna tanto formas de confesionalidad estatal con libertad religiosa como la construcción de la laicidad positiva, mientras que el modelo de «nación laica tolerante» es caracterizado por idénticos rasgos a los que yo utilicé para caracterizar la neutralidad estatal en materia religiosa: «permisivo con la religión», «no se compromete más con el ateísmo que con la religión», "no se define respecto de si alguna religión es la mejor, si es que alguna lo es... (Ruiz Miguel, 2010/2013, p. 76, n. 34).

Pero tiene igualmente razón Alfonso en pensar que la expresión «nación laica tolerante» resulta un tanto redundante y confusa como si la laicidad estatal no supusiera el ejercicio de la tolerancia y hubiera que explicitarla para no incurrir en una suerte de laicismo. Por mi parte, solo enfatizaría, a riesgo de ser reiterativo, que tal laicidad debe entenderse como laicidad activa, y no pasiva o neutral, precisamente para hacer viable el valor de la tolerancia, el estado del arte de la ciencia y el reconocimiento y promoción de los derechos humanos. 
Bibliografía

Bovero, M. (2002). Laicidad y democracia. Consideraciones sobre pensamiento laico y política laica. Nexos.

Cossío, J.R. (2008). Laicidad del Estado y libertad religiosa: cómo armonizarlas. Letras Libres, 112.

Dworkin, R. (2008). La democracia posible. Principios para un nuevo debate político. Barcelona: Paidós.

Dworkin, R. (2014). Religión sin Dios. México: Fondo de Cultura Económica.

Habermas J. y Ratzinger, J. (2008). Entre razón y religión. Dialéctica de la secularización. México: Fondo de Cultura Económica.

Habermas, J. (2006). Entre naturalismo y religión. Barcelona: Paidós.

Kolakowski, L. (1975). Neutrality and Academic Values. En A. Montefiore (ed.), Neutrality and Imparciality (pp. 72-86), Cambridge: Cambridge University Press.

Lafont, C. (2007). Democracia y deliberación pública. En R. Arango (ed.), Filosofía de la democracia. Fundamentos conceptuales. Bogotá: Siglo del Hombre Editores.

Lakke, C. (2007). En El Universal, sección El Mundo, 20 de julio.

Macedo, S. (1990). Liberal Virtues. Oxford: Oxford Clarendon Press.

Rawls, J. (1995). Liberalismo político. México: Fondo de Cultura Económica.

Ruiz Miguel, A. (2007). Laicidad, laicismo, relativismo y democracia. En R. Vázquez (coord.), Laicidad. Una asignatura pendiente (pp. 159 ss.), México: Coyoacán.

Ruiz Miguel, A. (2010/2012). La laicidad y el eterno retorno de la religión. En R. Vázquez, A. Ruiz Miguel y J.M. Vilajosana Rubio, Democracia, religión y Constitución. Madrid - México: Fundación Coloquio Jurídico Europeo Fontamara.

Ruiz Miguel, A. (2017). Razón pública, tolerancia e idiosincrasia religiosa. En J. Cerdio, P. de Larrañaga y P. Salazar (coords.), Entre la libertad y la igualdad (pp. 413-424). México: UNAM-ITAM-CEAD.

Ruiz Miguel, A. y Navarro-Valls, R. (2009). Laicismo y constitución. Madrid: Fundación Coloquio Jurídico Europeo.

Ruiz Miguel, A. (2020). Cuestiones de principios: entre política y Derecho. Madrid: Centro de Estudios Políticos y Constitucionales.

Salazar Carrión, L. (2007). Religiones, laicidad y política en el siglo XXI. En R. Vázquez (coord.), Laicidad. Una asignatura pendiente (pp. 149 ss.). México: Coyoacán.

Salazar Ugarte, P. (2020). Una laicidad muy religiosa. En R. Bacerra y J. Woldenbverg (coords.), Balance temprano. Desde la izquierda democrática. México: Grano de sal.

Sandel, M. (2011). Justicia. ¿Hacemos lo que debemos? Barcelona: Debate.

Savater, F. (2008). Siempre negativa, nunca positiva. En El País (pp. 31-32), 16 de octubre.

Tierno Galván, E. (1975), ¿Qué es ser agnóstico? Madrid: Tecnos.

Vázquez, R. (2010/2012). Laicidad, religión y deliberación pública. En R. Vázquez, A. Ruiz Miguel y J.M. Vilajosana Rubio, Democracia, religión y Constitución. Madrid - México: Fundación Coloquio Jurídico Europeo - Fontamara.

Vázquez, R. (2015). Derechos humanos. Una lectura liberal igualitaria. México: UNAM-ITAM-CEAD. 